\title{
Review: clonidine is effective for reducing symptoms of attention deficit hyperactivity disorder
}

Connor DF, Fletcher KE, Swanson JM. A meta-analysis of clonidine for symptoms of attention-deficit hyperactivity disorder. J Am Acad Child Adolesc Psychiatry 1999 Dec;38:1551-9.

QUESTION: In children with attention deficit hyperactivity disorder (ADHD), is clonidine effective and tolerable for improving symptoms of ADHD?

\section{Data sources}

Studies were identified by searching Medline (1980-99), PsycINFO (1984-99), Current Contents: Social and Behavioral Sciences (1996-9), Current Contents: Clinical Medicine (1996-9), non-peer reviewed research reports, book chapters, and reference lists.

\section{Study selection}

English language studies were selected if studies reported objective numerical data and outcome measures for the effect of clonidine on ADHD features, $\geq 1$ patient was involved, and the mean age for patients was $\leq 18$ years.

\section{Data extraction}

Data were extracted on study design; patient characteristics; daily dose; concomitant medications; treatment duration; comorbid diagnoses; adverse events; and clinician, parent, teacher, and overall ADHD symptom ratings. 2 reviewers assessed the quality of study methods (maximum score 8 points).

\section{Main results}

11 studies (8 randomised controlled trials) of 150 patients met the inclusion criteria. The mean age for patients was 10.6 years (range 8-16 y), the mean clonidine dose was $0.18 \mathrm{mg} /$ day (range 0.10-0.24 $\mathrm{mg} /$ day), and the mean length of treatment was 10.9 weeks (range 3-51wks). When studies showed statistically significant heterogeneity of effect size, they were grouped by the reviewers' quality rating scores. If statistical heterogeneity of effect sizes persisted, cluster analysis was used to form more homogeneous study groupings. Each group of studies showed that clonidine led to a reduction in clinician, parent, teacher, and overall ratings of ADHD symptoms (table). 1 study that reported extremely large effect sizes was removed from the analysis because of a suspected error in calculating the effect size.

\section{Conclusion}

In children with attention deficit hyperactivity disorder (ADHD), clonidine shows a moderate effect size in reducing ADHD symptoms.

\section{COMMENTARY}

Despite the concern raised about the lack of safety and efficacy data for the antihypertensive medication clonidine for children with ADHD, recent publications have documented its increasing use in children, even preschoolers, for treatment of ADHD. ${ }^{1}$ Questions about its safety, tolerability, and efficacy are not likely to be addressed by its manufacturer because it is out of patent and is not included in the US Food \& Drug Administration Modernization Act incentives. The meta-analysis by Connor $e t$ al of the literature since 1980 is a first step in breaking this stalemate. Why? It uses an evidence-based medicine approach to examine previous clinical reports. Clonidine appears to have moderately positive treatment effects for ADHD symptoms in children and adolescents when used in doses of 0.1-0.3 $\mathrm{mg}$ /day. As the authors show, this efficacy falls short of that reported for stimulants which, unlike clonidine, are approved for patients of this age. Furthermore, clonidine treatment is associated with many treatment emergent side effects, which must be monitored.

This study reviews the content of and the quality of 11 clinical reports involving 150 patients $<18$ years of age with ADHD. Although the authors rightfully caution the reader about the mix of methodologies, the paucity of placebo controlled studies in the dataset, and the small cell sizes for statistical analysis, they set minimal methodological standards to protect against bias (eg, type 1 errors that seem to be present in the studies judged methodologically weaker than average). Using these methods, the authors report that (1) the chance that a clonidine treated subject will show a better response than a control subject was $66 \%$; (2) children with ADHD without comorbid disorders appear to do best on clonidine; (3) parents reported more benefits from clonidine than do teachers and clinicians; and (4) parents' efficacy ratings correlated negatively with sedation caused by clonidine. This suggests the drug's ability to overcome insomnia in patients with ADHD - sometimes caused by stimulant medication treatment-does not explain parents' ratings of its efficacy.

Laurence Greenhill, MD New York State Psychiatric Institute New York, New York, USA

1 Zito JM, Safer DJ, dosReis S, et al. Trends in the prescribing of psychotropic medications to preschoolers. JAMA 2000;283:1025-30.
Source of funding: no external funding.

For correspondence:

Dr D F Connor,

Department of

Psychiatry, Room

S7-828, University of

Massachusetts Medical

School, 55 Lake

Avenue, North,

Worcester, MA 01655

USA. Fax +1508856

6426.
Reduction in attention deficit hyperactivity disorder symptoms for clonidine v placebo or no treatment in children

\begin{tabular}{|c|c|c|c|c|c|c|c|c|}
\hline \multirow[b]{2}{*}{ Ratings } & \multicolumn{2}{|c|}{$\begin{array}{l}\text { Number of } \\
\text { homogeneous } \\
\text { studies }\end{array}$} & \multicolumn{2}{|c|}{$\begin{array}{l}\text { Number of patients in } \\
\text { clonidine group }\end{array}$} & \multicolumn{2}{|c|}{ Weighted effect size } & \multicolumn{2}{|l|}{ p Value } \\
\hline & $\begin{array}{l}\text { Higher } \\
\text { quality } \\
\text { studies }\end{array}$ & $\begin{array}{l}\text { Lower } \\
\text { quality } \\
\text { studies }\end{array}$ & $\begin{array}{l}\text { Higher } \\
\text { quality } \\
\text { studies }\end{array}$ & $\begin{array}{l}\text { Lower } \\
\text { quality } \\
\text { studies }\end{array}$ & $\begin{array}{l}\text { Higher } \\
\text { quality } \\
\text { studies }\end{array}$ & $\begin{array}{l}\text { Lower } \\
\text { quality } \\
\text { studies }\end{array}$ & $\begin{array}{l}\text { Higher } \\
\text { quality } \\
\text { studies }\end{array}$ & $\begin{array}{l}\text { Lower } \\
\text { quality } \\
\text { studies }\end{array}$ \\
\hline Clinician & 3 & 2 & 36 & 25 & 0.43 & 4.07 & $<0.05$ & $<0.001$ \\
\hline Parent & 6 & 2 & 84 & 18 & 0.75 & 3.63 & $<0.001$ & $<0.001$ \\
\hline Teacher & 3 & 2 & 48 & 18 & 0.56 & 5.77 & $<0.004$ & $<0.001$ \\
\hline Overall & 6 & 4 & 84 & 43 & 0.58 & 4.26 & $<0.001$ & $<0.001$ \\
\hline
\end{tabular}

